\title{
PRESENÇA FEMININA NA ATIVIDADE VOLUNTÁRIA: UMA LEITURA A PARTIR DA BIOÉTICA
}

\author{
Lucilda Selli \\ Universidade do Vale dos Sinos - UNISINOS, São Leopoldo/RS, Brasil. \\ lucilda.selli@terra.com.br

\section{Volnei Garrafa} \\ Universidade de Brasília, Distrito Federal, Brasil. \\ volnei@unb.br
}

\begin{abstract}
Resumo: O artigo trata do significado atribuído à presença feminina majoritária em associações voluntárias. Esta é uma das temáticas que emergiu de pesquisa de doutorado, que teve como objetivo conhecer as motivações para o exercício do voluntariado e propor a solidariedade crítica como valor no campo da bioética e referência aos que exercem a atividade voluntária. A atividade voluntária como alvo que especifica uma atividade eminentemente feminina, tem a ver com as construções de voluntariado que pautaram a história. O enfrentamento e a desconstrução da visão e do papel assistencial atribuído ao voluntariado e a introdução do modelo orgânico de voluntariado implicam o reconhecimento da atividade voluntária no seu papel social, independente do sujeito, masculino ou feminino, que o pratica.
\end{abstract}

Palavras-chave: Feminino. Voluntariado. Solidariedade. Bioética.

\begin{abstract}
The article addresses the meaning ascribed to the prevalent female presence in volunteer associations. This is a topic that emerged from one doctorate research, of which the purpose was to determine the motivations for volunteering and propose critical solidarity as a value in the field of bioethics and a guideline for those who participate in voluntary activities. The voluntary work as a target that outlines an eminently female activity is related to volunteering constructs pervading history. Dealing with and deconstructing the view and the assisting role attributed to volunteering and the introduction of an organic volunteering model imply the acknowledgment of voluntary work in its social role, regardless of the volunteer's gender, male or female.
\end{abstract}

Key words: Female. Volunteering. Solidarity. Bioethics. 


\begin{abstract}
A
teorização sobre a problemática da participação majoritária da mulher em atividades voluntárias está voltada à ampliação do debate sobre o tema do voluntariado orgânico no campo da bioética.

O artigo aborda as razões alegadas, pelos voluntários pesquisados, como justificáveis para a participação feminina majoritária em atividades de cunho voluntário. Este é um dos aspectos que emergiu de uma pesquisa recente que analisou e propôs a solidariedade crítica como valor a ser incorporado na agenda bioética do século XXI, como instrumento no aprimoramento da democracia e na diminuição das disparidades sociais (SELLI \& GARRAFA, 2005).

Entende-se por solidariedade crítica a capacidade do agente de discernir, ou seja, de possuir critérios capazes de ajudá-lo a discriminar as dimensões social e política, que estão indissociavelmente presentes na relação solidária. Assim, a solidariedade não se esgota enquanto relação típica da sociedade civil. Ao contrário, possui um elemento político que tem como referência o Estado. A capacidade de entender essa dimensão política, que se refere à cidadania e à possibilidade de intervir de forma ativa na definição de políticas públicas, também caracteriza essa dimensão crítica da solidariedade (BOBBIO, 1995).

As razões alegadas como justificativas para a maior participação da mulher na atividade voluntária, ofereceram elementos importantes para construir a visão de voluntariado que os atores possuem sobre a sua própria atividade voluntária e para propor um modelo de voluntariado com enfoque social, tendo como ferramenta de intervenção a solidariedade crítica.

Em sua tese de doutorado Gonçalves estabelece a solidariedade como um dos pressupostos da Bioética de Intervenção, para fazer frente à desconstrução do preconceito em torno do HIV/Aids, (GONÇALVES, 2005). Em essência, o que está ficando claro no contexto dos países periféricos é a necessidade de buscarem por meio da pesquisa respostas bioéticas próprias, adequadas a cada contexto sócio-cultural (GARRAFA, 2004). É, também, nesta perspectiva, que se entende ser a solidariedade um valor que instrumentaliza os atores sociais voluntários a fazerem frente aos preconceitos em torno do feminino/voluntário e terem ações voluntárias que possibilitem a emergência de sujeitos coletivos.
\end{abstract}

\title{
Alguns Dados do Contexto
}

Propõe-se para o Brasil uma bioética pautada na solidariedade como um dos valores a orientar a área da saúde de uma sociedade que possui amplas parcelas da população num quadro permanente de pobreza e marginalização. 
Neste cenário, as pessoas que exercem a prática voluntária possuem como uma de suas ferramentas a solidariedade, como instrumento para romper a identidade de excluídos de muitos dos destinatários de suas ações.

Para Maia, o voluntariado é uma das atitudes mais solidárias. Para ela, muitas instituições somente sobrevivem com a participação desse agente, pelo seu trabalho voluntário comprometido; trata-se do voluntariado que doa parte de seu tempo na realização de trabalhos sociais (MAIA, 2000).

No caso brasileiro, mesmo constatando-se que ao longo dos últimos 50 anos tem-se investido recursos na área da saúde, tal investimento não tem sido suficiente para alterar o quadro de pobreza e exclusão de parcelas significativas da sociedade. Instituições da sociedade civil, como algumas organizações não-governamentais têm adotado a solidariedade como característica de suas ações, dando mostra de comprometimento para com a sociedade na busca de alternativas que minimizem o quadro de injustiça ocasionado pela exclusão social.

O voluntariado é uma ação que tem como função ser mediador na condução das questões sociais, pautando-se, pelo menos teoricamente, em uma política ancorada no valor da solidariedade, com capacidade de gerar transformações tanto conjunturais como estruturais para a busca da justiça e da dignidade humana.

O espaço público constitui-se o lugar onde a ação, como mediadora da vida política, vai sintetizar o simbólico e o real presente nas coletividades. O voluntariado como espaço para expressão de uma solidariedade comprometida com a busca de um projeto comum, capaz de ser assumido por uma comunidade como proposta operacional e como referencial simbólico de sua subjetividade, pode constituir-se em uma ação política por excelência (BAVARESCO, 2004).

Um estudo sobre a Radiografia Bioética do Brasil, destacou a necessidade de buscar perspectivas alternativas para as teorias bioéticas tradicionais (GARRAFA, 2000). A proposta da solidariedade, como instrumento que orienta o serviço voluntário qualificado como social, é uma tentativa de introduzir progressivamente um modelo de bioética - a Bioética de Intervenção - condizente com a nossa realidade e comprometida com o aprimoramento da democracia e a diminuição das disparidades sociais.

\section{A Ética do Cuidado}

O cuidado estava presente na antiga literatura romana pela palavra cura, traduzida por cuidado, atenção, interesse. A radical importância do cuidado, 
para o ser humano, aparece no mito, chamado de Cuidado, recolhido pelo autor romano Higino (REICH, 1995).

Heidegger fundamenta o cuidado antropologicamente. Este não é um conceito ao lado de outros, mas um ponto central de seu sistema filosófico (HEIDEGGER, 1988). O cuidado torna-se um modo de ser do ser-aí (Dasein). Entende o cuidado como uma dimensão fontal, ontológica do ser humano. Distingue entre taking care of e care of. O primeiro corresponde à preocupação pelas necessidades e carências dos outros, o segundo identifica-se com a solicitude pelas pessoas, por grupos humanos etc. O primeiro remete à sobrevivência e a finitude do ser humano, o segundo supera e transcende a ansiedade da preocupação, desenvolvendo as potencialidades da solicitude que caracteriza o ser humano (REICH, Op. cit.).

A fundamentação antropológica do cuidado abriu a perspectiva para a construção de uma proposta ética do cuidado. Em 1982 com a publicação da obra de Carol Gilligan In a Different Voice emergiu a perspectiva do cuidado na ética, como resultado de um estudo sobre o desenvolvimento moral das mulheres realizado pela autora. Gilligan mostrou que as mulheres elaboram e avaliam conflitos morais de modo diferente dos homens.

Para a autora os homens procuram analisar os componentes do dilema, separando-os em indivíduos isolados e tentando definir o direito de cada um na perspectiva da justiça. As mulheres buscam ver o conjunto das relações implicadas na situação, tentando detectar as conexões e procurando cuidar das inter-relações. Assim, o cuidado não é uma teoria, mas uma orientação ética que enfatiza a preocupação e o discernimento, os hábitos e as tendências de interpretação, a seletividade de habilidades e a destreza. A ética do cuidado de Gilligan concentra-se mais na atitude ou caráter da pessoa do que no comportamento ou ato corretos.

Para entender o estudo de Gilligan sobre o desenvolvimento moral das mulheres é necessário apresentar o pensamento de Kohlberg sobre o desenvolvimento moral. O autor buscou em seus estudos conhecer as características estruturais do raciocínio moral de um indivíduo e o processo de desenvolvimento de tais características. Concluiu que o desenvolvimento moral é universal para todos os humanos, sejam mulheres ou homens, e evolui de maneira progressiva e em diferentes níveis a formas superiores de maturidade moral.

Os níveis progressivos de desenvolvimento moral significariam passar da formulação de juízos puramente heterônimos, a um raciocínio ético autônomo. A autonomia representa a condição e a justiça, o conteúdo formal da moralidade madura. A teoria de Kohlberg está baseada na pura avaliação 
cognitiva de julgamentos morais e nisso está sua debilidade como sistema de educação para valores morais.

Examinando o processo de pesquisa de Kohlberg, Gilligan constatou que as avaliações de sobre o desenvolvimento moral levantadas naquele estudo estavam fundadas em critérios masculinos, já que, segundo o autor, as mulheres tinham dificuldade para chegar a juízos correspondentes ao nível pós-convencional. Conforme Gilligan o problema não estava nas mulheres, mas na metodologia utilizada. Na controvérsia que se seguiu, Gilligan provou que as mulheres elaboram e avaliam conflitos morais de modo diferente que os homens. Para ela os homens assumem o enfoque da justiça na solução dos problemas morais, enquanto que as mulheres adotam uma postura do ponto de vista do cuidado. O problema moral para as mulheres é uma questão de cuidado e responsabilidade nos relacionamentos em vez de uma pergunta sobre direitos e normas que caracteriza a ética da justiça.

Gilligan articula a discussão entre a ética da justiça e a ética do cuidado. Entende que são duas orientações éticas diferentes, mas que devem se complementar e não duas teorias que se opõem. O homem, mais inclinado para o esquema da justiça, precisa educar-se para a perspectiva do cuidado. A mulher, mais tendente ao cuidado, necessita despertar para o enfoque da justiça.

O voluntário ao eleger a solidariedade como valor que orienta sua atividade necessita incorporar e articular a ética da justiça e a ética do cuidado à sua prática.

\section{Metodologia}

O projeto de pesquisa maior, do qual resulta o presente artigo, foi desenvolvido junto a cinco associações de voluntários atuantes, entre outras, no Instituto Nacional do Câncer (INCA) do Rio de Janeiro/Brasil (SELLI, 2002). Os dados sobre as associações foram obtidos no contato com as mesmas e por meio do Relatório de Atividades do INCA - 1998/1999 (BRASIL, 1999). A população na qual foi escolhida a amostra é de 731 voluntários, que constituem as cinco associações definidas para participar da pesquisa.

O critério de inclusão dos sujeitos da pesquisa foi de serem voluntários devidamente legalizados, conforme a Lei $\mathrm{n}^{\circ}$ 9.608, de 18 de fevereiro de 1998, pertencentes às associações escolhidas para compor a amostra. Os critérios de exclusão foram: participantes de associações religiosas, com um total de 119 voluntários; e voluntários não registrados nas associações e em 
período de adaptação, completando o número de 120 voluntários. Na soma total, foram excluídos 239 voluntários, resultando um desvio padrão estatístico de $0,05 \%$. Foram acrescentados cinco voluntários a este total para prevenir possíveis perdas e assim foi obtido o número final de 110 voluntários amostrados. A amostra ficou assim distribuída: Associação dos Amigos da Criança com Câncer: 30 voluntários; Associação dos Amigos do Instituto Nacional do Câncer: 30 voluntários; Grupo de Apoio Integrado de Voluntários à Oncologia de Adultos e Adolescentes: 22 voluntários; Associação de Recreação e Apoio à Criança com Câncer: 15 voluntários; Associação de Voluntários em Artes e Apoio aos Pacientes do Hospital de Oncologia: 13 voluntários.

Para a abordagem dos sujeitos da pesquisa optou-se pela estratégia metodológica em dois diferentes momentos. O primeiro momento foi de aplicação de um questionário com 16 perguntas fechadas, dividido em duas partes: uma introdutória, com sete itens, com dados gerais dos entrevistados; e a outra referente a suas motivações com relação ao tema da solidariedade. O segundo momento foi a aplicação de uma entrevista semi-estruturada e gravada, dirigida a sete voluntários que, no processo de aproximação, contato e aplicação dos questionários, mostraram-se mais envolvidos com o tema, com especial capacidade de interpretação dos fatos e, acima de tudo, que demonstraram inquietude frente ao assunto. Foram distribuídos 110 questionários, retornando 106 e, dentre estes, um entrevistado recusou-se a participar da pesquisa, devolvendo o questionário em branco. O trabalho de campo foi desenvolvido entre outubro e dezembro de 2000. Para a elaboração e análise dos dados foi usado como referência Minayo (MINAYO, 1996).

\section{Significados Atribuídos à Atividade Voluntária Feminina}

Quando se decidiu conhecer as motivações para a atividade voluntária e saber o lugar que a solidariedade ocupa entre os sujeitos da pesquisa, tornou-se necessário investigar o motivo atribuído à significativa maior adesão das mulheres em tal atividade, reconstruindo assim a visão de voluntariado que os atores possuem, objetivando conhecer a percepção e movimento de passagem entre o voluntariado tradicional e o voluntariado social do grupo pesquisado.

Este artigo busca especificamente uma aproximação da leitura feita pelos sujeitos da pesquisa sobre as razões alegadas à participação majoritária da mulher na atividade voluntária. Os entrevistados foram convidados a 
estabelecer os motivos que, segundo eles, são indicadores da participação predominante da mulher no serviço voluntário, aspecto que pode proporcionar o conhecimento do significado que essa atividade tem entre os voluntários, em sua maioria, mulheres.

Pelos dados estatísticos, constatou-se que a presença da mulher no trabalho voluntário atingiu 89,5\% da amostra, o que ilustra o peso de sua participação na atividade voluntária. A descrição, a seguir, sobre as características femininas, representa a visão que a mulher ainda tem de si mesma como voluntária e a força que os indicadores sociais construídos à sua volta, ao longo da história, exercem em suas próprias representações e no desempenho de seus papéis sociais.

As falas das mulheres entrevistadas estão impregnadas dos estereótipos que estabelecem suas características. A "sensibilidade" foi indicada como primeiro motivo de ter a mulher maior participação na atividade voluntária, perfazendo o total de $27,5 \%$ das respostas. Na opinião de $20 \%$ dos voluntários, o "amor" explica a maior inserção da mulher em atividades voluntárias. O "instinto materno" foi indicado por 17,5\% como razão para a maior participação da mulher em associações voluntárias e o fator "tempo disponível" somou um total de 15,2\%. Outra razão alegada foi o fato de as mulheres serem "mais emotivas", com 7,6\% das respostas.

Analisando-se as motivações indicadas constata-se que, em sua maioria, prevaleceram os estereótipos construídos ao longo do tempo em nossa cultura, sobre os vários papéis da mulher na sociedade: mãe; dona-de-casa com tempo disponível; capaz de expressar seu amor aos filhos e, por extensão, aos demais; e responsável pelo cuidado da família. Tais opiniões atingiram o total de 72,6\% dos entrevistados, representando, em valores absolutos, a opinião de 75 entrevistados.

Confirmam os dados as falas registradas nas entrevistas semiestruturadas, nas quais um entrevistado relata: "a mulher tem a tendência de se envolver mais com atividades voluntárias por ser mais sensível, é mais aberta às necessidades dos outros". Neste sentido, outro entrevistado diz que "a mulher leva consigo o instinto materno, então, ela é mais sensível e amorosa com as pessoas necessitadas". Um terceiro acrescenta que "a mulher, diante do sofrimento, é mais emotiva, se doa mais, percebe mais a dor do outro". Além desses, outros motivos foram verbalizados como justificativa para a maior adesão da mulher às atividades voluntárias: "ao longo da história, a mulher ocupou o lugar de doméstica; isso fez com que dispusesse de mais tempo para atividades voluntárias"; "o fato do sustento da família estar 
na dependência do homem favoreceu a mulher dispor de mais tempo para estas atividades não remuneradas da sociedade"; "muitas vezes, a mulher, para ter uma ocupação fora de casa ou ocupar o seu tempo ocioso, dedicouse ao trabalho voluntário".

O livro Caring: nurses, women and ethics aborda detalhadamente os efeitos perniciosos que a eticidade, baseada em uma ética do cuidar, tem sobre as experiências das mulheres. A autora enfatiza que o esforço teórico de papéis femininos considerados naturalizantes, como é o caso da maternidade, traz conseqüências que podem ser extremamente destrutivas para profissões predominantemente femininas. De acordo com as mesmas colocações, a utilização da fórmula "mulher - boa mãe - boa enfermeira" reforça, nas relações profissionais, a subordinação, delimitando uma divisão de trabalho baseada em uma hierarquia de gênero, atribuindo com isso à enfermeira um papel passivo nessa relação (KUHSE, 1997).

Neste contexto é importante ter presente também os estudos de Nodding sobre o fato das mulheres, freqüentemente, definirem-se tanto como pessoas quanto como agentes morais em termos de sua capacidade de cuidar. Para a autora, as estruturas psicológicas profundas podem ser responsáveis por este modo de definição (NODDING, 2003). Há diferenças típicas entre os homens e as mulheres em sua busca da ética nos relacionamentos humanos. Essa compreensão contrapõe-se à maneira de interpretar práticas voluntárias femininas simplesmente como decorrentes da natureza das mulheres.

Os serviços de saúde, ao refletirem de forma inequívoca a estrutura social dominante, evidenciam uma prática do cuidado com o viés da subordinação feminina. Estes dados revelam uma visão tradicional, assistencialista e paternalista da atividade voluntária, não adequada a uma atividade voluntária de cunho crítico e transformador. A industrialização, a urbanização, o aumento da escolarização feminina, dentre outros múltiplos fatores, modificaram boa parte dos papéis sociais femininos, além de definir outros, como, por exemplo, o de cônjuge cabeça-do-casal. Segundo dados oficiais, cerca de 25\% das mulheres com união estável no Brasil são responsáveis pelo sustento familiar. Por este dado é possível admitir que a visão tradicional do voluntariado, como atividade tipicamente feminina, exercida por mulheres na terceira idade e desocupadas, já não mais corresponde à realidade do país. Neste sentido diz um entrevistado: "As pessoas ainda acreditam que a atividade voluntária é praticada por pessoas ociosas, principalmente mulheres. É uma mentalidade machista. Temos que trabalhar para 
modificar essa visão distorcida da atividade voluntária". Outro assim se pronuncia: "Ainda há uma visão muito elitista no nosso país sobre a atividade voluntária. Ela era vista como privativa de pessoas ricas, com tempo disponível para práticas assistencialistas". Outro diz:

"A cultura do voluntariado como atividade para mulheres desocupadas, perdurou durante muito tempo. É lamentável que essa visão distorcida do serviço voluntário ainda encontre guarida em muitos indivíduos. Isso prejudica a atividade voluntária, porque quem é preconceituoso não irá exercê-la".

Também o próprio objeto da atividade voluntária, a prestação do serviço propriamente dita, é visto de forma estereotipada, como relatado em algumas entrevistas: "A atividade voluntária é vista como algo insignificante, uma atividade piedosa, de importância menor na sociedade". Referindo os estereótipos criados em torno da atividade voluntária como sendo eminentemente feminina, destaca um entrevistado: "A população brasileira precisa de conscientização. Cada pessoa deve sentir-se participante da vida do país". Outro refere: "Na medida em que cada pessoa assume a sua parcela de responsabilidade e toma consciência disto, com certeza haverá mudanças na sociedade".

Por estes depoimentos percebe-se com clareza o significado que a atividade voluntária deve ocupar na vida das pessoas, tornando-as integradas à sociedade e, como tal, co-responsáveis pelo bem-estar coletivo.

\section{Considerações Finais}

O reconhecimento do perfil social das mulheres, as características próprias da personalidade feminina e as suas experiências cotidianas, ditadas de acordo com os processos biológicos e sociais, contribuíram para situá-las como estando mais próximas de uma "natureza" universalizante, em contraposição aos objetivos "culturais", traduzidos como processo criativo, atribuído ao homem. É essa diferença de status que contribui para a subordinação, controle e manipulação das mulheres pelos homens, de acordo com Rosaldo e Lamphére (ROSALDO \& LAMPHÉRE, 1979). Embora evoque e faça uma abordagem séria das experiências da vida moral feminina, sejam 
elas relacionadas ao cuidado dos outros, como crianças, idosos, doentes e pacientes, sejam elas relacionadas à manutenção de uma infra-estrutura familiar, que dê suporte para a manutenção do status masculino na sociedade, a ética do cuidar perpetua a subordinação feminina, reforçando os estereótipos sociais tradicionalmente associados aos papéis de gênero masculinos e femininos (CARSE \& NELSON, 1999). Essa visão mantêm as mulheres circunscritas ao lugar que sempre ocuparam, reforçando os padrões de opressão e submissão impregnados nos homens e mulheres por um processo cultural que outorga o poder aos homens e conforma as representações, calcadas em uma visão eminentemente masculina.

Embora os voluntários entrevistados não tenham manifestado rupturas na complementaridade das ações voluntárias, como resultado das relações de poder, trouxeram com clareza os estereótipos e apontaram saídas em prol da eficácia de seu fazer. A tentativa de conhecer o lugar atribuído à mulher na atividade voluntária, nos dias atuais, pelo conhecimento das motivações, dá visibilidade ao juízo pouco criterioso que ainda permeia as representações sobre a atividade voluntária. O enfrentamento e a superação de representações tão arraigadas e a busca da independência estariam sob a responsabilidade das próprias mulheres, que individual e coletivamente devem assumir o ônus da rebeldia (KUHSE, Op. cit.).

A construção da categoria "solidariedade crítica" implica olhar de modo questionador as dificuldades que as mulheres enfrentam para abandonar olhares distorcidos sobre seu fazer voluntário. A solidariedade crítica, como valor, deve ser pautada por uma bioética capaz de avaliar e aproximar o discurso concreto sobre a igualdade e incorporá-lo à prática cotidiana, produzindo relações mais equilibradas entre homens e mulheres (SELLI \& GARRAFA, Op. cit.).

Uma proposta social de voluntariado deve considerar a história e a trajetória real de tal atividade. O interesse de fomentar o voluntariado como coadjuvante para as questões de bem-estar social, deve levar em consideração tal trajetória e permitir a passagem processual do modelo tradicional para um novo modelo socialmente comprometido e transformador, adequado aos tempos atuais, porém, ainda mesclado pelas representações da tradição.

A reconstrução das representações sobre as mulheres na atividade voluntária implica o enfrentamento das relações de poder, o rompimento com a naturalização do potencial feminino e a visibilização da sua capacidade de resistir e de inventar novos caminhos. 


\section{Referências bibliográficas}

BAVARESCO, S. M. R. O discurso sobre o voluntariado na Universidade do Vale do Rio dos Sinos - UNISINOS. Cadernos IHU idéias, ano 2, n. 26, 2004.

BOBBIO, N. et al. Dicionário de política. Brasília, Editora UnB, 7ª ed., 1995, vols. I e II.

BRASIL. Ministério da Saúde / Instituto Nacional do Câncer. Relatório de atividades. Rio de Janeiro, 1999.

CARSE, A.L.; NELSON, H.L. Reabilitating care. In: DONCHIN, A.; PURDY, L.M. (ed.). Recent Embodying Feminist Bioethics Advances. Boston, Rowman \& Littlefield Publishers, 1999.

GARRAFA, V. Radiografia bioética de um país / Brasil - A bioethical radiograph of Brazil. Acta Bioethica. Organización Panamericana de la Salud - OPAS/OMS; Santiago, Chile, 6 (1):165-181, 2000.

. O Brasil deve buscar respostas bioéticas próprias. In: Radis; Rio de Janeiro,

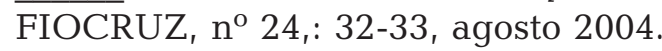

GONÇALVES, E. H. Desconstruindo o preconceito em torno do HIV/Aids na perspectiva da bioética de intervenção. Tese de Doutorado em Ciências da Saúde - área de concentração em Bioética. Universidade de Brasília, Brasília, 2005.

KUHSE, H. The slumbering giant. In: KUHSE, H. Caring: nurses, women and ethics. Oxford, Blackwell Publishers, 1997.

MAIA, M. Jornal do Conselho Regional de Serviço Social. $1^{\circ}$ Região, no 54 - Porto Alegre, Março, 2000.

MINAYO, M.C. O desafio do conhecimento: Pesquisa qualitativa em saúde. Rio de Janeiro, HUCITEC/ABRASCO, 1996.

NODDING, N. Uma abordagem feminina à ética e à educação moral. O Cuidado. São Leopoldo, Unisinos, 2003.

ROSALDO, M. Z.; LAMPHERE, L. Introdução. In: ROSALDO, M.Z.; LAMPHERE, L. (Orgs.) Mulher, cultura e sociedade. São Paulo, Paz e Terra, 1979.

SELLI, L. Bioética, Solidariedade critica e voluntariado orgânico. Tese de Doutorado em Ciências da Saúde - área de concentração em Bioética. Universidade de Brasília, Brasília, 2001.

SELLI, L. \& Garrafa, V. Bioética, solidariedade crítica e voluntariado orgânico. Revista de Saúde Pública, São Paulo/SP, v. 39, 2005, no prelo.

Recebido em 9/5/2005

Aprovado em 21/5/2005 